\title{
FLY ASH BASED GEOPOLYMER COMPOSITES PARTIALLY REPLACED WITH SILICA FUME: AN EXPERIMENTAL INVESTIGATION
}

\author{
Mukhallad M. Al-mashhadani' ${ }^{1}$, Orhan Canpolat ${ }^{2}$, Yurdakul Aygörmez ${ }^{2}$, \\ Mucteba Uysal ${ }^{3}$, and Furkan Sahin ${ }^{3}$
}

${ }^{1}$ Istanbul Gelişim University, Civil Engineering Department, Avcilar Campus, Istanbul, Turkey, E-mail: 〈mashhadani@gelisim.edu.tr>,

${ }^{2}$ Yildiz Technical University, Faculty of Civil Engineering, Civil Engineering Department, Davutpasa Campus, Istanbul, Turkey, E-mail: 〈canpolat@yildiz.edu.tr〉, <aygormez@yildiz.edu.tr>, ${ }^{3}$ Istanbul University Cerrahpasa, Engineering Faculty, Civil Engineering Department, Avcilar campus, Istanbul, Turkey, E-mail: <mucteba.uysal@istanbul.edu.tr>, <furkansahintr@gmail.com>

\begin{abstract}
Nowadays, the environmental impact which is caused by the industrial development specially in construction section have led to an increasing interest in geopolymer field and thereby have promoted the research in terms of full replacement of Portland cement binder and feasible utilization of waste materials. In this paper, an attempt was done to fabricate a binding matrix that is totally cement free and based on eco-friendly materials. The effect of adding silica fume on strength properties, physical properties and resistance to abrasion were studied. In general, silica fume was found to enhance the investigated properties due to the fineness of silica fume particles which generally formed geopolymeric composites with more compact matrix. The geopolymeric matrix which is fabricated with the presence of silica fume has shown an obvious improvement in terms of physical properties. Moreover, the compactness of the matrix led to a good performance regarding the abrasion resistance, to be more specific, the abraded surface was more resistant to weight loss after adding silica fume. In addition to that, an acceptable degree of correlation was obtained when the results of the studied properties were linked, results from strength tests and the ones from non-destructive tests were having a good degree of correlation.
\end{abstract}

Keywords: Sustainable; Geopolymer; Fly Ash; Silica fume; Slag; Abrasion; Water absorption; Voids ratio

\section{INTRODUCTION}

The cementitious binders which represent the backbone of the present construction industry. Their production, however, is not classified among the green production processes around the world. $\mathrm{CO}_{2}$ emissions which are caused by cement production process represent $5-7 \%$ of the total $\mathrm{CO}_{2}$ emissions worldwide [1,2]. These emissions are currently considered as one of the most effective reasons of the global warming phenomena. 
In the same concern, a vast quantity of industrial by-products and waste materials is disposed to landfills while their use within the construction field has proved to be in benefit of improving the properties of the resulting matrix. Fly ash, ground granulated blast furnace slag, rice husk ash, palm oil fuel ash, copper and zinc slag are examples of such materials which could be successfully used as a partial or full replacement to Portland cement [3].

In the light of these facts, a considerable number of research attempts has been carried out to synthesize new binders which contain less or no cementitious materials [4]. Among many alternative binding systems in which less or no Portland cement is used and industrial byproducts or waste materials are used instead, geopolymer technology, represents one of the most current research interests due to its success in terms of full replacement to Portland cement, incorporating environmental-friendly materials as precursors, and good properties of the manufactured composites [5-7].

Based on the reaction between an alumina-silica rich source and an alkaline solution, geopolymeric matrix is mainly consisted of ( $\mathrm{Si}-\mathrm{O}-\mathrm{Al}-\mathrm{O})$ polymeric bonds which are stronger when compared to the cementitious bonds [8]. Fly ash based geopolymer composites are classified among the most popular materials within geopolymer field. Use of fly ash as a main material in the geopolymeric matrix is convenient in terms of cost, effective in terms of strength properties and durability characteristics.

$\mathrm{Xu}$ et al. [9] conducted a study on the inclusion of heavy metals on the performance of fly ash geopolymers regarding strength and leaching properties. They concluded that the immobilization of the used metals could be effectively obtained while manufacturing the geopolymeric matrix, also, alkali activator and heavy metal type were found to cause a significant effect on the chemical and physical characteristics of the resulted samples.

Bakharev [10] carried out an investigation on the heat effect of fly ash geopolymers with sodium and potassium activators. Strength tests, shrinkage behavior and microstructural analyses were conducted in this research. Under high temperatures from 800-1200oC, the research findings revealed the fact the manufactured composites yielded large decrease in terms of strength and high shrinkage pattern and therefore not suitable for the applications in these temperatures.

Diaz et al. [11] performed a study on different fly ashes performance within the geopolymeric matrix in terms of chemical composition, strength behavior and setting time along together with the microstructural characterization. Conclusions stated that the particle size and the degree of the vitrification of the fly ash represented the main factors which affect the characteristics of the resulted specimens.

Okoye et al. [12] evaluated the effect of adding silica fume to fly ash geopolymers, they tested this matrix which was cured under a high temperature with respect to other investigations. Tensile and compressive strengths were determined with the fresh properties of the manufactured concretes. Silica fume was generally found to enhance the strength results.

Duan et al. [13] combined both using silica fume within the geopolymeric system and testing that system to the elevated temperatures exposure. As expected, silica fume was found to beneficial in improving the resulted matrix. Exposure to higher temperatures, however, exhibited a strength loss and a decrease in physical behavior regardless of the added silica fume.

Okoye et al. [14] studied the inclusion of silica fume in fly ash GPC and investigated the resistance of the final product against chloride and sulfuric attacks. Deterioration rates in 
strength and weight losses were tested for the fabricated concretes and compared to an ordinary OPC concrete mix. As a general conclusion, the existence of silica fume resulted in an improvement in terms of weight loss and strength performance after exposure to the chemical solutions.

This investigation aimed firstly to obtain a geopolymeric matrix with totally green materials based on waste materials. Moreover, the experiments focused on the effect of adding silica fume on strength properties, physical properties and abrasion resistance of the manufactured samples.

\section{MATERIALS}

Fly ash (class F) which is correspondent to specific standard ASTM C618 [15] was provided from Cates electrical production Inc. whereas Slag (GGBS) was obtained from Bolu cement Company. The chemical solution was a mix of sodium silicate and sodium hydroxide (12 M). Standard was correspondent to BS EN 196-1 [16] and silica fume was obtained from Eti Antalya Electrometallurgy Inc., the details of all the aforementioned powders are listed in table 1.

Table 1. Chemical composition of Fly Ash, GGBS and Silica Fume (\%).

\begin{tabular}{|l|l|l|l|l|l|l|l|l|l|l|}
\hline & $\mathrm{SiO}_{2}$ & $\mathrm{Al}_{2} \mathrm{O}_{3}$ & $\mathrm{Fe}_{2} \mathrm{O}_{3}$ & $\mathrm{CaO}$ & $\mathrm{MgO}$ & $\mathrm{SO}_{3}$ & $\mathrm{Na}_{2} \mathrm{O}$ & $\begin{array}{l}\text { Free } \\
\mathrm{CaO}\end{array}$ & $\mathrm{Cl}^{-}$ & LOI \\
\hline FA & 54.08 & 26.08 & 6.681 & 2.002 & 2.676 & 0.73 & 0.79 & 0.11 & 0.092 & 1.36 \\
\hline GGBS & 40.55 & 12.83 & 1.10 & 35.58 & 5.87 & 0.18 & 0.79 & - & 0.0143 & 0.03 \\
\hline SF & 91.57 & 0.38 & 0.15 & 0.32 & 4.05 & ----- & 0.55 & --- & ----- & 1.68 \\
\hline
\end{tabular}

\section{EXPERIMENTAL PROCEDURE}

Samples were prepared using a manual mixer. The mixing process requires a high speed mixer in order to achieve a good degree of consistency. The mixing ratios are illustrated in table 2 . After the mixing process is finished, the resulted mix was cast into the molds designated in this study, namely $50 \mathrm{~mm}$ side cubes for compressive strength , $40 \times 40 \times 160$ prisms for flexural strength, and $\Phi 10 \mathrm{~mm} \times 7.5 \mathrm{~mm}$ cylinders for abrasion resistance. The manufactured samples are then heat cured in an oven for 24 hours and left for the intended tests. The aforementioned tests were done in accordance with ASTM C 109[17] (comp. strength), ASTM C 348 [18] (flexural strength) and ASTM C 944 (abrasion resistance) [19].

Table 2. Mixing proportions of manufactured geopolymer composites (g).

\begin{tabular}{|l|l|l|l|l|}
\hline FlyAsh+ Silica Fume & Sand & Slag & $\begin{array}{l}\mathrm{NaOH} \\
(12 \mathrm{M})\end{array}$ & $\mathrm{Na}_{2} \mathrm{SiO}_{3}$ \\
\hline 450 & 1237.5 & 60 & 50 & 175 \\
\hline
\end{tabular}


Note: silica fume is partially replaced with fly ash (in case of $10 \mathrm{SF}, \mathrm{FA}=405 \mathrm{~g}, \mathrm{SF}=45 \mathrm{~g}$ )

\section{RESULTS AND DISCUSSION}

\section{Physical Properties}

In general, all of the fabricated samples exhibited an improvement with respect to the control sample. The addition of silica fume proved to be in benefit of improving the performance of the matrix in terms of physical properties. The ratios of improvement reached up to $22 \%$ in terms of water absorption and up to $29.44 \%$ in terms of voids ratio. The results of the 2 nd category are presented in Table 3.

Table 3 Physical properties of the 2nd category's samples

\begin{tabular}{|l|l|l|l|}
\hline Mix ID & Water absorption $(\boldsymbol{\%})$ & Unit weight $\left(\mathbf{g} / \mathbf{c m}^{\mathbf{3}}\right)$ & Voids ratio (\%) \\
\hline $10 \mathrm{SF}$ & 6.36 & 2.25 & 11.31 \\
\hline $20 \mathrm{SF}$ & 6.14 & 2.32 & 11.03 \\
\hline $30 \mathrm{SF}$ & 6.02 & 2.41 & 10.24 \\
\hline
\end{tabular}

Further addition of silica fume led to better physical properties because the fine particles of this material is responsible for transferring the matrix into the nanoscale and thereby reduce the amount of pores inside the geopolymeric matrix. Thus, a significant improvement in terms of transport properties could be observed when silica fume was used in this investigation. Figure 1 shows the improvement ratios of water absorption and voids ratio, respectively.

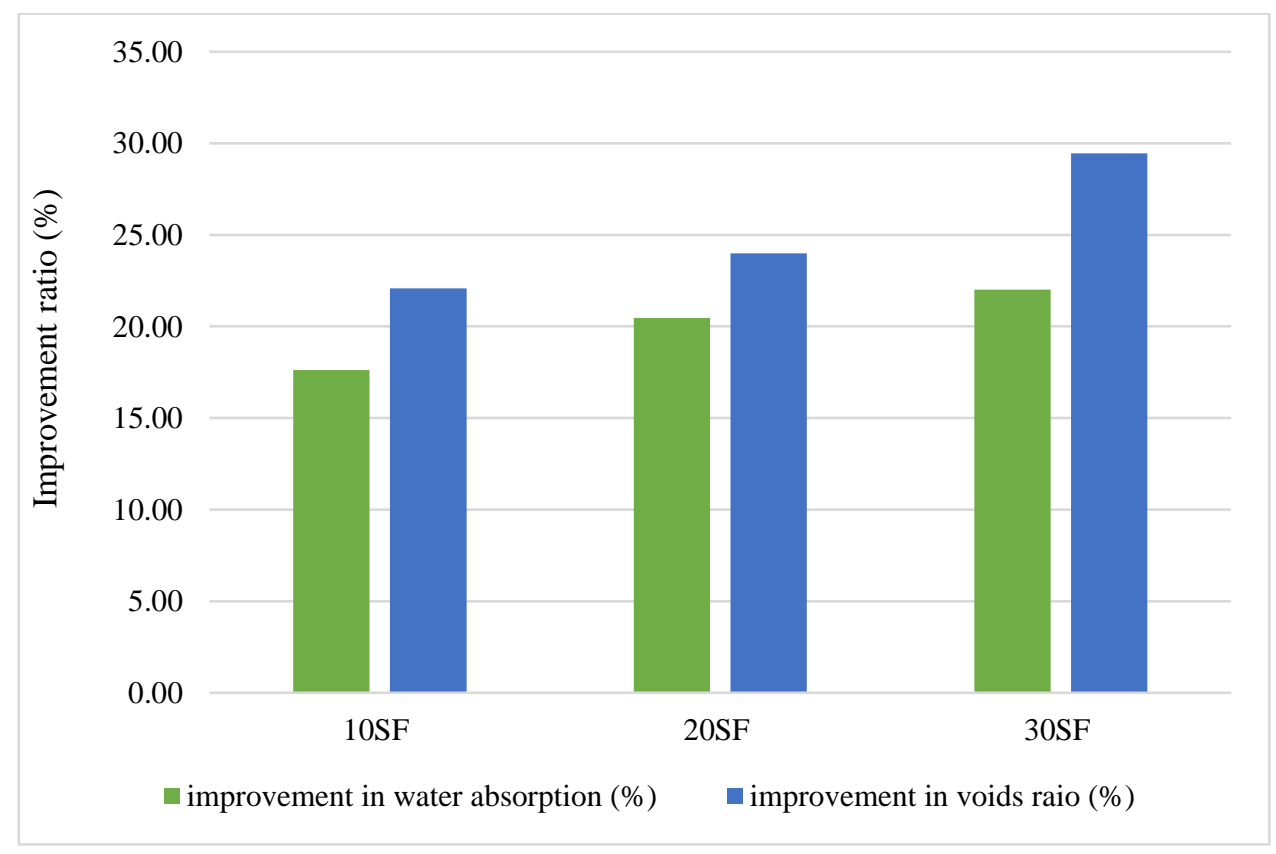

Figure 1 Improvement in physical properties-2nd category 


\section{Strength Properties}

The results which are given in Tables 4 and 5 show a certain improvement in strength results when silica fume is used as a partial replacement with fly ash. The pozzolanic properties and the particles features of silica fume are responsible for the obtained improvement in the manufactured samples, silica fume particles are finer than those of fly ash and therefore this leads to a final matrix with more degree of compactness and good microstructural bonding. Moreover, the high silica content in silica fume results in higher Si/Al ratio and hence a stronger geopolymeric matrix. The results which are obtained in this category are correspondent to the previous findings in this concern [12-14].

Table 4 Compressive strength results- $2^{\text {nd }}$ category $(\mathrm{MPa})$

\begin{tabular}{|l|l|l|l|l|}
\hline MIX ID & 7 DAYS & IR & 28 DAYS & IR \\
\hline $10 \mathrm{SF}$ & 62.63 & 3.98 & 62.84 & 3.41 \\
\hline $20 \mathrm{SF}$ & 62.86 & 4.37 & 63.17 & 3.95 \\
\hline $30 \mathrm{SF}$ & 62.91 & 4.45 & 63.37 & 4.28 \\
\hline
\end{tabular}

Table 5 Flexural strength results- $2^{\text {nd }}$ category $(\mathrm{MPa})$

\begin{tabular}{|l|l|l|l|l|}
\hline MIX ID & 7 DAYS & IR & 28 DAYS & IR \\
\hline $10 \mathrm{SF}$ & 8.146 & 3.98 & 8.476 & 0.24 \\
\hline $20 \mathrm{SF}$ & 8.565 & 9.33 & 8.624 & 1.99 \\
\hline $30 \mathrm{SF}$ & 8.537 & 8.97 & 8.709 & 2.99 \\
\hline
\end{tabular}

\section{Ultrasonic Pulse Velocity Test}

In order to evaluate the homogeneity of the fabricated matrix and to investigate the effect of different conditions on the manufactured composite, nondestructive tests are always in benefit of determining the performance of the matrix when other test results are definitive. Among those tests, ultrasonic pulse velocity test is classified as one of the most important in situ tests to understand the pattern of the obtained results. Silica fume partial replacement resulted in certain improvement to the obtained results. According to the results in Table 6 Silica fume fine particles were responsible for a faster wave flow and hence better results. Also, the 
increasing silica fume content positively affected the trend of the obtained results which indicated that higher dosages of silica fume result in more compact geopolymeric matrix which allows a faster wave transmission.

Table 6 Ultrasonic pulse velocity values- ${ }^{\text {nd }}$ cat
\begin{tabular}{|l|l|l|}
\hline MIX ID & UPV 7 & UPV 28 \\
\hline 10 SF & 3515 & 3579 \\
\hline $20 S F$ & 3531 & 3576 \\
\hline $30 S F$ & 3527 & 3592 \\
\hline
\end{tabular}

\begin{abstract}
Abrasion Resistance
Abrasion resistance or wear resistance of binders is one of the tests that represent a main point of interest to many researchers, it is very important to determine the wear resistance for concrete or screed finishing surfaces. This test could be performed according to different conditions and regarding various standard specifications such as ASTM C944, ASTM C779M, and Böhme test which is based on the British standards. In this investigation, an attempt was carried out to find out the effect of the added materials on the abrasion resistance of the resulted specimens. Standard specification ASTM C944 was followed when performing the test, specimens were abraded using a rotating cutter which contains dressing wheels, then, the abrasion process was made for three 2-minute time intervals (totally 6 minutes) for every specimen. The weight loss is then recorded after the first abrasion and an average weight loss or abrasion resistance is calculated. As seen from Figures 2 and 3, the samples yielded better results when compared to the control samples. The existence of silica fume increased the degree of chemical bonding within the manufactured geopolymeric matrix. Hence a specimen which is chemically more stable is able to achieve better results. Moreover, increasing silica fume content was found to beneficial in enhancing the surface characteristics of the fabricated composites.
\end{abstract}

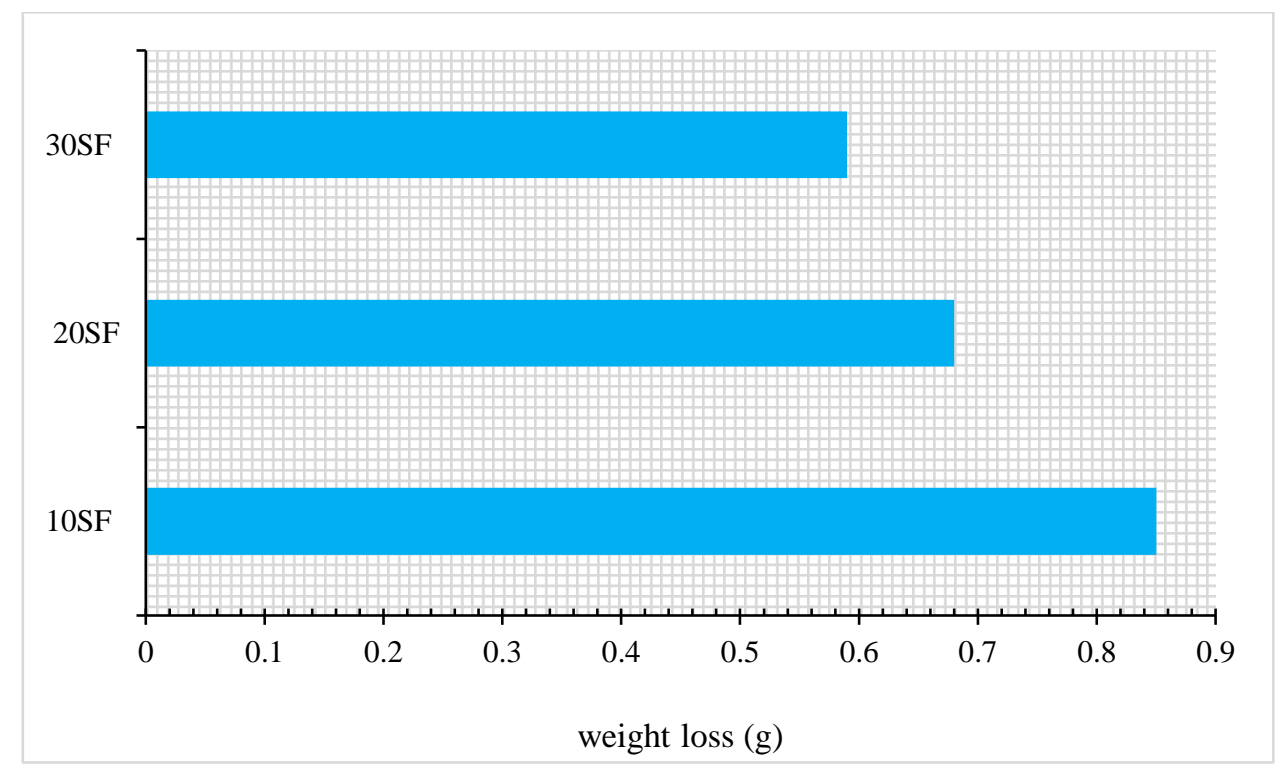

Figure 2 Average weight loss 


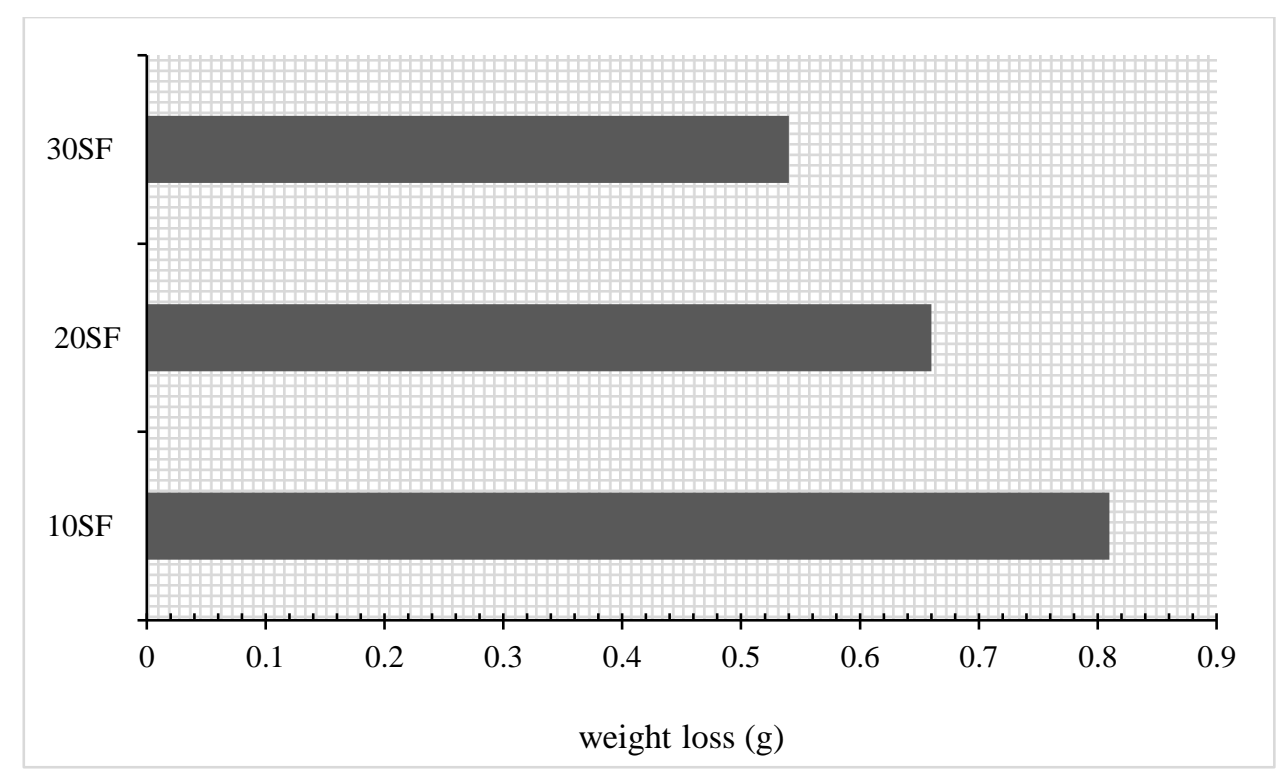

Figure 3 weight loss per abrading

\section{Correlation Relationships Between Some Investigated Properties}

To evaluate the degree of consistence between the some investigated properties, an attempt was carried out to determine the correlation between strength properties and non-destructive tests results. Correlation relationships were obtained for compressive strength- ultrasonic pulse velocity and flexural strength- abrasion resistance test. $\mathrm{R}^{2}$ is a factor that represents the degree of correlation between the investigated properties, if this factor yields a value of more than 0.75 , then a certain trend of correlation could be seen through performing this calculation. The samples yielded a similar trend of correlation, Figures 4 and 5 show the significant homogeneity of the investigated properties, this is mainly related to the fact that the existence of silica fume resulted in reducing the pores within the matrix and thus an obvious improvement.

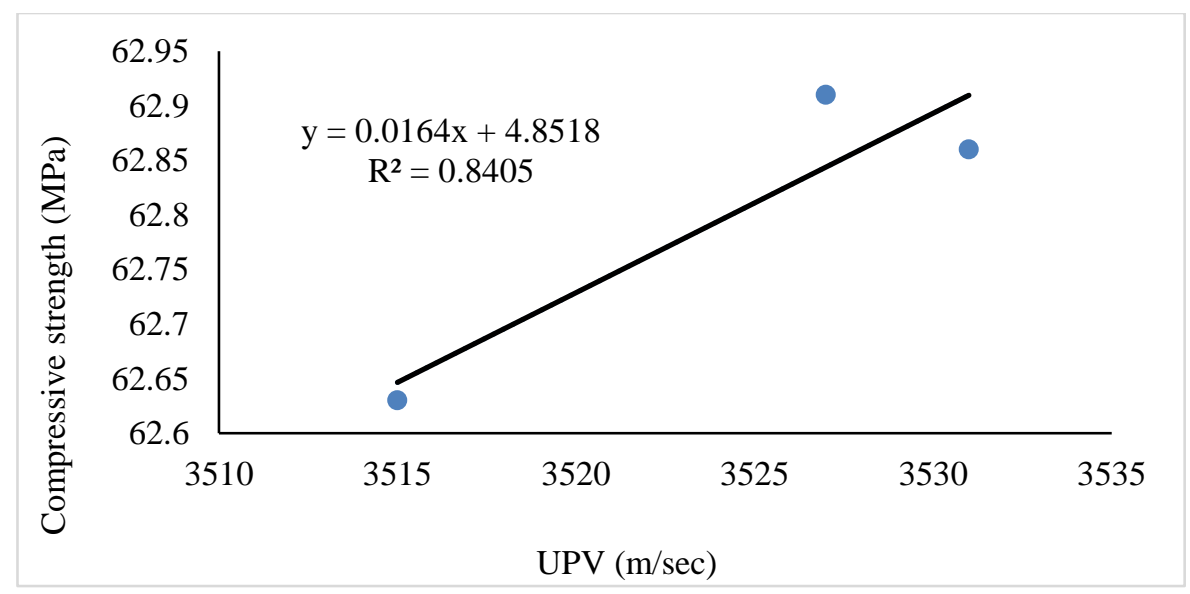

Figure 4 Correlation relationship between compressive strength and UPV results 


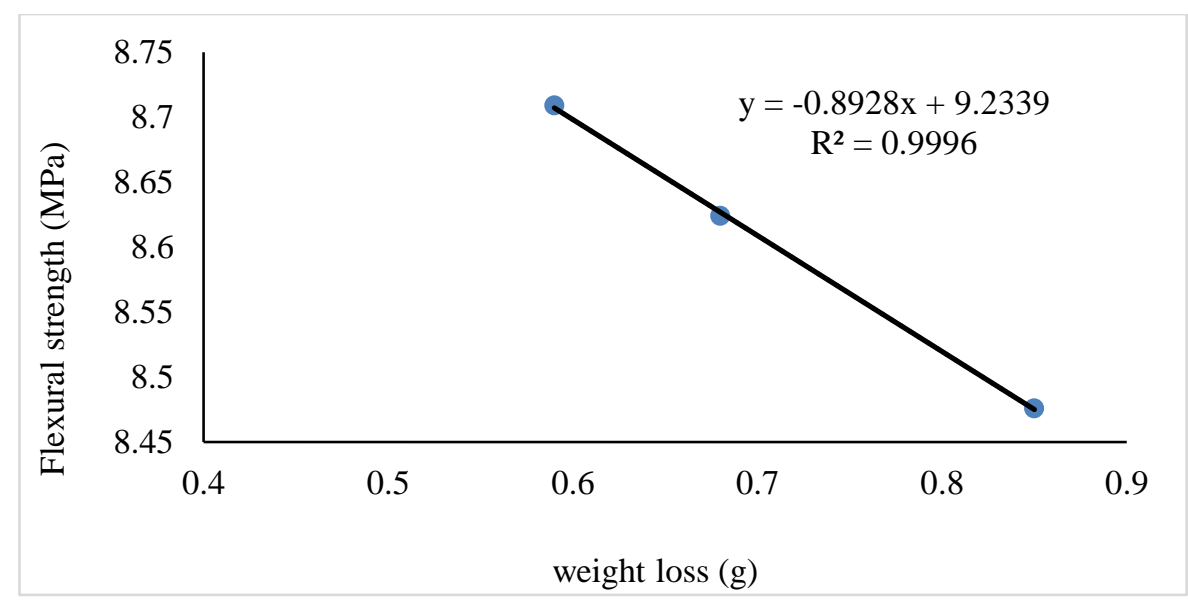

Figure 5 Correlation relationship between flexural strength and abrasion resistance results

\section{CONCLUSIONS}

- As a general conclusion, geopolymer samples exhibited a significant improvement in all of the studied properties when compared to the conventional cementitious control samples. The nature and the compactness of the geopolymeric matrix were the main reason behind the obtained results.

- The results revealed the fact that the samples were stronger and more durable in all aspects.

- The properties of silica fume samples were better results when compared to the other samples, silica fume acts as micro filler and hence improves the microstructural composition of the matrix by reducing the pores within it.

\section{REFERENCES}

[1] Benhelal, E., Zahedi, G., Shamsaei, E. and Bahadori, A., (2013). "Global strategies and potentials to curb CO2 emissions in cement industry." Journal of Cleaner Production, 51:142161.

[2] Gartner, E., (2010). "Industrially interesting approaches to "low-CO2" cements." Cement and Concrete Research, 34:1489-1498.

[3] Alnahhal, M. F., Alengaram, U. J., Jumaat, M. Z., Alqedra, M.A, Mo K. H. and Sumesh M., (2017). "Evaluation of Industrial By-Products as Sustainable Pozzolanic Materials in Recycled Aggregate Concrete.” Sustainability, 9(767):1-23.

[4] Davidovits, J., (1994). "Global Warming Impact on the Cement and Aggregates Industries." World Resource Review, 6:263-278.

[5] Davidovits, J., (1989). "Geopolymers and Geopolymeric Materials.” Journal of Thermal Analysis, 35:429-441.

[6] Xu, H. and Van Deventer, J. S. J., (2000). "The geopolymerisation of alumino-silicate minerals." International Journal of Mineral Processing, 59:247-266. 
[7] Duxson, P., Fernandez-Jimenez, A., Provis, J.L., Lukey, G.C., Palomo, A. and Van Deventer, J.S.J, (2007). "Geopolymer technology: the current state of the art." Journal of Materials Science, 42:2917-2933.

[8] Van Deventer, J.S.J., Provis, J.L., Duxson, P. and Lukey, G.C., (2007). "Reaction mechanisms in the geopolymeric conversion of inorganic waste to useful products." Journal of Hazardous Materials, 139:506-513.

[9] Xu, J.Z., Zhou, Y.L., Chang, Q. and Qu, H.Q., (2006). "Study on the factors of affecting the immobilization of heavy metals in fly ash-based geopolymers." Materials Letters, 60:820822 .

[10] Bakharev, T., (2006). "Thermal behaviour of geopolymers prepared using class F fly ash and elevated temperature curing." Cement and Concrete Research, 36:1134-1147.

[11] Diaz, E.I., Allouche, E.N. and Eklund, S., (2010). "Factors affecting the suitability of fly ash as source material for geopolymers." Fuel, 89:992-996.

[12] Okoye, F.N., Durgaprasad, J. and Singh, N.B., (2016). "Effect of silica fume on the mechanical properties of fly ash based-geopolymer concrete." Ceramics International, 42:3000-3006.

[13] Duan, P., Yan, C. and Zhou, W., (2017). "Compressive strength and microstructure of fly ash based geopolymer blended with silica fume under thermal cycle." Cement and Concrete Composites, 78:108-119.

[14] Okoye, F.N., Prakash, S. and Singh, N.B., (2017). "Durability of fly ash based geopolymer concrete in the presence of silica fume." Journal of Cleaner Production, 149:1062-1067.

[15] ASTM C618 (C), in: Standard Specification for Coal Fly Ash and Raw or Calcined Natural Pozzolan for Use, Annual Book of ASTM Standards, 2010, pp. 3-6.

[16] BS EN 196-1(2016), BSI Standards Publication Methods of testing cement Part 1: Determination of strength.

[17] ASTM C109/109M, Standard Test Method for Compressive Strength of Hydraulic Cement Mortars (Using 2-in. or [50-mm] Cube Specimens) 1, Chemical Analysis, (C109/C109M - 11b), 2010, pp. 1-9.

[18] ASTM C348, in: Standard Test Method for Flexural Strength of Hydraulic-Cement Mortars ASTM C348, Annual Book of ASTM Standards, 1998, pp. 2-7.

[19] ASTM C944/C944 M, in: ASTM C944/C944M - 12 - Standard Test Method for Abrasion Resistance of Concrete or Mortar Surfaces by the Rotating-Cutter Method, ASTM International, 2012. 